\title{
RUIN PROBABILITY ON STORM AND FLOOD DISASTER RISK FINANCE IN MULTIPLE RAILWAY BUSINESSES
}

\author{
Katsumasa OHORI ${ }^{1}$ \\ ${ }^{1}$ Member of JSCE, Associate Professor, Iwate Prefectural University \\ (152-52, Sugo, Takizawa, Iwate 020-0693, Japan) \\ E-mail: katsu_o@iwate-pu.ac.jp
}

\begin{abstract}
Given that the losses incurred from natural disasters are uncertain and characterized by considerable fluctuation, restoration funds intended for disaster preparation are usually calculated based on the assumption of probable maximum loss (PML). However, preparing for PML via the acquisition of sufficient funding is difficult for railway companies that suffer from financial difficulties. These companies urgently need to implement risk financing (RF) strategies against frequent storm and flood disasters to avoid insolvency. Meanwhile, there is also a great need for an analysis of storm and flood disaster RF with targeting multiple railway businesses for reasons of group insurance or consolidated accounting. To address these issues, this study develop a financial risk model that considers the disaster-related characteristics and financial conditions of multiple railway businesses and establish a ruin probability model for the mathematical analysis of the procurement of funds, including initial reserves, insurance money, and subsidy. These models are designed to help multiple railway businesses prepare for losses estimated on the grounds of data on past damages. Case studies that feature actual data on railway companies across Japan are conducted to demonstrate and verify the effectiveness of the proposed models.
\end{abstract}

Key Words : railway, natural disaster, storms and floods, restoration, risk finance, ruin probability

\section{INTRODUCTION}

Every year, tremendous losses in terms of lives and property occur in Japan because of natural disasters, such as typhoons, torrential rains, heavy snowfall, earthquakes, and tsunamis. For example, in the period of FY1950-2014, as many as 30 railways in Japan are found to be abolished after suffering damages from natural disasters, and an annual average of 0.45 railways has been abolished after suffering damages from natural disasters ${ }^{1), 2}$. In recent years, following Typhoon No. 14 in 2005, a third-sector railway company called Takachiho Railway was forced to go out of business after suffering severe damage. The company collapsed despite its insurance coverage and assistance from the subsidy systems of the national and local governments because it could not repay its share of disaster restoration costs.

The misfortunes discussed above highlight the fact that procuring natural disaster recovery funds that require a huge one-time payment is critical for the survival of railway companies owning huge railway structures. If these enterprises are seriously stricken by natural disasters and fail to acquire recovery resources, they will inevitably face bankruptcy or the discontinuance of their businesses. Such outcomes, in turn, will significantly affect the society and economy of communities located along railways. Avoiding these situations necessitates implementing a financial measure referred to as risk financing (RF). The problem is that although RF for natural disasters is important for both railway companies and local residents, the rate at which such practice is exercised remains $l^{3}{ }^{3)-6)}$. Many railway businesses in Japan are private companies operating under the principle of financial independence, and they are confronted with difficulties in procuring natural disaster recovery funds because of the problems related to public financial support, insurance, and other social systems $^{1)-6)}$.

As the storm and flood disasters, out of the natural disasters, account for $90 \%$ of the disasters that have led to the abolishment of railways and $92 \%$ of the disasters affecting third-sector railway companies. These disasters are thus overwhelming risk factors for enterprises engaged in the railway business ${ }^{1)-3}$. 
While the storm and flood disasters have been increased and intensified globally due to climate change, etc. ${ }^{7)-9)}$ (Fig. 1), the damages on railways caused by storm and flood disasters are also increased and intensified, leading to the increased premium of the natural disaster insurance of civil engineering

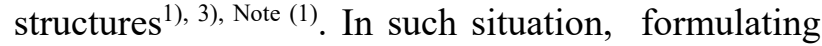
disaster RF strategies against storms and floods is becoming progressively essential for railway companies that grapple with financial difficulties (small and medium-sized private railway companies, third-sector railway enterprises, etc.).

To find a solution, Ohori and Morichi $(2016)^{2}$ verified the probability distribution of losses caused by storm and flood disasters, and used statistical data as grounding in proposing that the ruin probability of a railway business plays a vital role in the mathematical analysis of disaster RF strategies against the aforementioned calamities. While, as described later in Section 2.(3), there is an urgent need to conduct analysis that focus specifically on multiple railway businesses.

Responding to the requirements of railway companies, the present study put forward a mathematical ruin probability model of storm and flood disaster RF for multiple railway businesses. The effectiveness of the model was verified using actual data on the damage caused by storms and floods in Japan.

Some may insist that securing disaster recovery funds beforehand is unnecessary for railway companies that do not intend to continue operations even if they have invested in such resources. However, the enterprises of interest in this work were assumed to operate railways that are indispensable to communities where residents commute to offices, schools, or hospitals and localities where tourism promotion is important. This indispensability means that acquiring funding for disaster recovery and restoration is a crucial task for these companies.

The rest of the paper is organized as follows. Section 2 discusses the fundamental viewpoint that underlies the present research in relation to extant studies on natural disaster RF in the railway industry. Section 3 describes the modeling of the aggregate loss that multiple-railway businesses bear when storms and floods occur. Section $\mathbf{4}$ presents the ruin probability model formulated in this work and its mathematical foundation. Section 5 expounds on case studies that were conducted on the basis of actual railway losses from storms and floods and using the models proposed in Sections 3 and 4. Section 6 concludes the paper with implications and recommendations for future research.

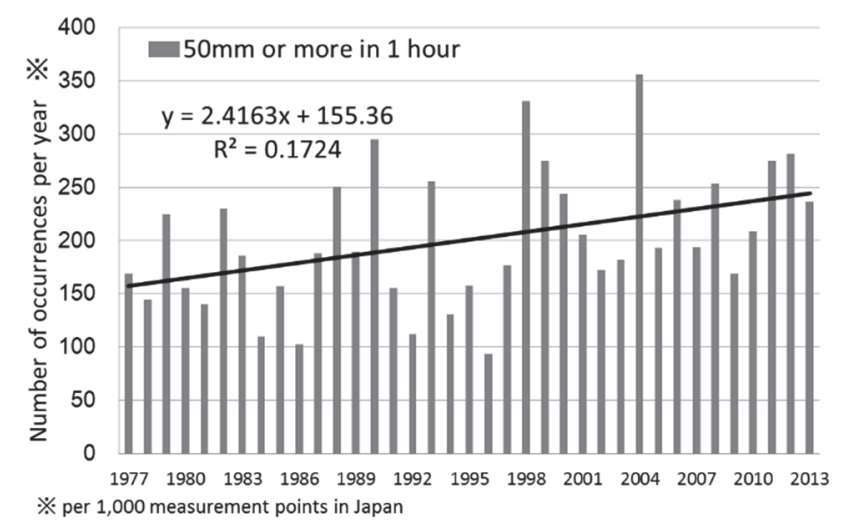

Fig.1 Increasing incidence of torrential rainfall in Japan (Source: Japan Meteorological Agency).

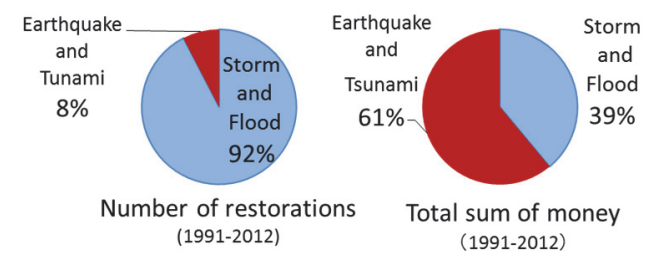

Fig.2 Restoration incurred from natural disasters that strike thirdsector railways in Japan ${ }^{2}$.

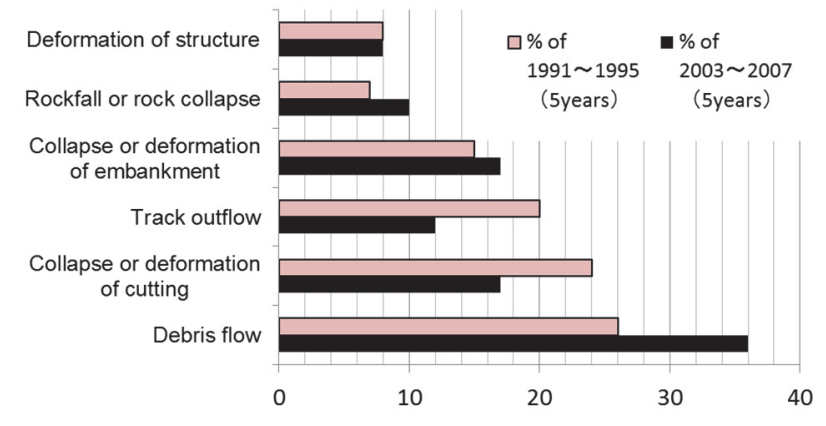

Fig.3 Change in natural disaster classification in Japan Railway companies (Source: Ohta and Sugiyama ${ }^{10)}$ ).

\section{FUNDAMENTAL VIEWPOINT}

\section{(1) Characteristics of natural disasters that affect the railway industry in Japan}

Natural disasters that damage railway structures in Japan include torrential rains, typhoons, heavy snowfall, earthquakes, tsunamis, and volcanic eruptions ${ }^{10}$. Out of the natural disasters that led to the abolishment of railways in Japan, storm and flood disasters account for $90 \%$, and earthquakes and tsunamis account for $10 \%{ }^{1)}$. 2 . Also, among the natural disasters that severely struck third-sector railway companies nationwide from 1991 to 2012, storm and flood disasters account for $92 \%$, and earthquakes and tsunamis account for $8 \%{ }^{2), 3)}$ (Fig. 2). In short, these statistics 
indicate a close similarity and the ratio between a group of storm and flood disasters and a group of earthquakes and tsunamis is approximately 9:1 in terms of the number of losses.

Ohta and Sugiyama (2009) ${ }^{10)}$ carried out research on the railway structures owned by Japan Railway (JR) companies to determine trends related to natural disaster occurrence. The authors found the following insights (Fig. 3):

1) The collapse or deformation of railway cuttings account for about $30 \%$ of the total in the past, but this proportion has decreased, owing to the progress achieved through improvement measures for cutting slopes.

2) The proportion of damage arising from disasters such as debris flow, which is beyond the control of railway companies, is increasing. This increase is attributed primarily to the torrential rainfall, and number of typhoons striking Japan, among other factors.

With regard to reinforcing of civil engineering structures against natural disasters, major private railway enterprises, such as JR companies, are aggressively investing in disaster prevention measures, including slope and aseismic reinforcement ${ }^{10)}$, but the small and medium-sized private railway companies and the third-sector railway companies, which are in financial difficulty, lack funds to invest in disaster prevention, and disaster prevention measures have

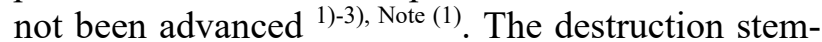
ming from these calamities has also increased and intensified because of the effects of climate change.

\section{(2) Previous studies on natural disaster RF for railway businesses}

Given that RF is part of risk management (RM), the framework of RM is reviewed first. Then, RF-related studies are reviewed in line with risk assessment and risk treatment.

\section{a) Review of RM framework}

RM has been advanced in various fields, including fire protection, traffic safety, occupational safety, information security, product design, and medical safety. Also, the globalization of the world economy has driven the globalization of risks. Coping with such situation, international standardization of RM became necessary, and the international standard ISO 31000 (Risk Management - Principles and Guidelines) on RM was issued in $2009^{11)}$, 12). At the same time, the international standard on RM terminology, ISO Guide 73 (Risk Management - Vocabulary) was revised $^{12)}$. The International Organization for Standardization has prepared the comprehensive standard on RM for the first time ${ }^{12)}$. The feature of ISO 31000 is that it focuses on the risks of organizations including corporations and defines RM for organization

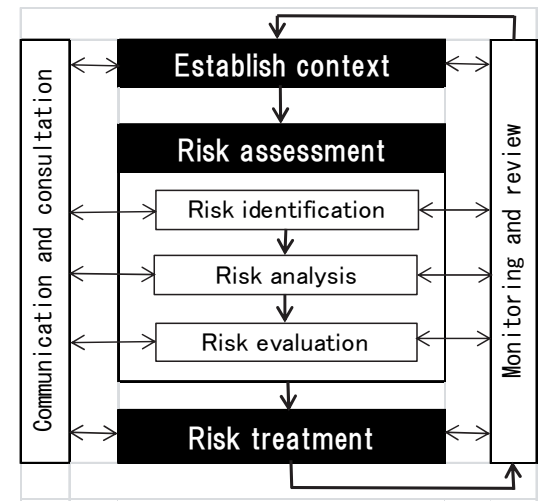

Fig.4 Risk management process based on ISO $31000^{11)}$.

Table 1 Risk treatment measures applied in railway businesses.

\begin{tabular}{l|l||l}
\hline \multicolumn{2}{c||}{ Classification } & \multicolumn{1}{c}{ Measures } \\
\hline \hline $\begin{array}{l}\text { Risk } \\
\text { Control } \\
(\text { RC) }\end{array}$ & Prevention & $\begin{array}{l}\text { Slope reinforcement, } \\
\text { Aseismic reinforcement }\end{array}$ \\
\cline { 2 - 3 } & $\begin{array}{l}\text { Mitigation } \\
\text { (reduction) }\end{array}$ & $\begin{array}{l}\text { Early Warning Systems, } \\
\text { Disaster Reduction Drill, } \\
\text { Business Continuity Plan (BCP) }\end{array}$ \\
\hline $\begin{array}{l}\text { Risk } \\
\text { Finance } \\
(\text { RF) }\end{array}$ & Transfer & $\begin{array}{l}\text { Insurance, subsidy, } \\
\text { Alternative Risk Transfer (ART) }\end{array}$ \\
\cline { 2 - 3 } & Retention & $\begin{array}{l}\text { Appropriation from internal } \\
\text { reserves, fund balance, etc. }\end{array}$ \\
\hline
\end{tabular}

management. In addition, the common RM process in various fields has been standardized as shown in Fig. 4. Then in Japan, JIS Q 31000 (Risk Management - Principles and Guidelines) was issued in 2010 based on ISO $31000^{12)}$.

Natural disaster RF for railway businesses is often implemented on the basis of the framework shown in Fig. 4. Many previous studies on RF included analyses of risk assessment and treatment.

\section{b) Review of risk assessment}

In recent years, the process by which risks arise from natural disasters has been elucidated from the viewpoints of engineering and science, and the idea of risk assessment has become popular. Methods of calculating an estimated amount of damages caused by natural disasters also come into wider use. For storm and flood disasters, guidelines such as those related to prediction based on flood simulation have been developed. With respect to earthquakes and tsunamis, damage prediction based on the ground motion prediction models and seismic design guidelines has been produced ${ }^{13)}$. In Japan, the main government's Cabinet Office and local governments have published hazard maps of each region with expecting the maximum probable disasters, including flood, inlandwater, landslides, tidalwaves ${ }^{14)}$.

Research anchored in economic perspectives has been carried out to examine approaches to the economic evaluation of risks related to natural disasters. 
These methods encompass social cost-benefit analysis and the econometric modeling of disaster prevention under the assumption that the maximum probable disaster will take place ${ }^{15)-17)}$. The economic domain has also increasingly delved into the equity-efficiency trade-off in the regulation of natural disaster insurance ${ }^{18)}$ and financing intended to deal with risks presented by natural catastrophes. Foot (1999) ${ }^{19)}$, for instance, concentrated on the natural catastrophes in the United States to probe into the demand for catastrophe insurance protection, the limitations of supply, alternative mechanisms for shifting risk, capital markets as viable tools for absorbing risk, and other similar issues. In the Japanese context, Kobayashi and Yokomatsu $(2002)^{16)}$ presented cost-benefit analyses of catastrophe-related risk mitigation and summarized research issues to be solved in the future. Tatano and Takagi (2005) ${ }^{17)}$ systematized disaster prevention in Japan from the perspective of risk management and described methods of risk assessment for natural catastrophes.

In the finance and insurance field, the theory dealing with bankruptcy problem following huge loss risk due to the Great Depression or catastrophic natural disasters, etc. is called risk theory and has developed uniquely in mathematical analysis such as the Cramér-Lundberg model and extreme value theory ${ }^{20)-22}$. Mathematical modeling research and case studies that combine the Cramér-Lundberg model with simulations of earthquakes and floods have been performed primarily to analyze the viability of insurance systems against the risk of natural catastrophes on the basis of stochastic optimization. Representative examples are the studies of Ermoliev et al. $(2000)^{23)}$, Ermolieva et al. $(2003)^{24)}$, Amendola et al. $(2013)^{25)}$, and Ermolieva et al. $(2017)^{26)}$

From the viewpoint of structural engineering, many engineering studies have been conducted to date on natural disaster risk assessment of railway structures ${ }^{9}$. In respect of storm and flood disaster risk assessment, research and practical application have progressed, for example, in rainfall risk assessment ${ }^{27)}$ of the slopes along railways. Regarding the earthquake risk assessment, it was difficult to implement an engineering analysis of earthquake damages on the ground and structures from an epicenter and along railway lines with a total length of several tens to hundreds kilometers. However, in recent years, practical analysis methods are being developed by the previous studies ${ }^{28)}$ and Railway Technical Research Institute $^{29)}$.

Many of such previous studies and practical methods have been used for medium and long-term investment in disaster prevention and financial stabilization for the government agencies and large enterprises. Such analysis methods have the characteristics of a long time frame from several decades to several hundred years, and the amount of losses equals the maximum in the past or the probable maximum loss (PML). In other words, there are many engineering analyses assuming the probable largest catastrophic disasters such as Ise-wan Typhoon or Great East Japan Earthquake.

\section{c) Review of risk treatment}

The risk treatment depicted in Fig. 4 illustrates the implementation phase of RM. Associated implementation measures are classified into seven in ISO $31000^{11)}$, but in practical contexts, these courses of action can be categorized into two: risk control (RC) and RF. On this basis, concrete examples of risk treatment in the railway industry were identified and presented in Table 1. As torrential rains or earthquakes occur frequently in Japan, structual studies on avoidance or prevention of the risks have been accumulated $^{9)}$, including construction methods of strengthened structures, disaster prediction systems. Software studies including BCP have been accumulated since around 2000 and led to wider use to reduce the risks of anticipated large-scale disasters such as plate-type giant earthquakes ${ }^{14)}$.

On the other hand, with regard to natural disaster RF for transport infrastructure including railways, airports, ports, etc., Uchida et al. $(2009)^{4)}$ conducted questionnaire survey on all transport business operators to find out RF statuses and issues, and recommended the necessity of the national government's involvement in the subsidy system for disaster restoration and insurance systems. Based on the result of the survey by Uchida et al. (2009) $)^{4}$, Morichi (2009) and Nozawa et al. $(2010)^{6)}$ pointed out the inadequacy in the natural disaster insurance of civil engineering structures in railway business as well as the subsidy system for disaster restoration under the Act on Improvement of Railroads and Rail Tracks. Additionally, Ohori ${ }^{1)-3)}$ has made clear the following characteristics of natural disaster RF in railway business, based on an interview survey ${ }^{\text {Note }}$ (1).

1) Natural disaster RF implemented by major railway companies differs from that applied by small and medium-sized railway firms.

2) Major private railway companies that are well managed anticipate the PML caused by earthquakes or tsunamis in many cases. Their risk treatment measures include the active implementation of RC measures, such as seismic strengthening, and advanced RF schemes, such as earthquake insurance and alternative risk transfer (ART) ${ }^{30)}$.

3) Primary concern of the railway businesses in financial difficulty (mainly small and mediumsized private railway companies, third-sector railway companies ${ }^{31)}$ ) are frequently occurring storm and flood disasters. Many of them have pointed 
out that RF in preparation for earthquakes and tsunamis is difficult and such railway companies cannot help but rely entirely on public financial support.

4) While struggling to improve the bottom line of annual financial statements or maintain cash flow, the railway businesses in financial difficulty hope to mitigate burdens of insurance premiums, etc., and also have strong requirements for short-term, effective RF to avoid cash shortage at the time of recovering from disasters.

With the results above as reference, Ohori and Morichi (2016) ${ }^{2)}$ has analyzed the actual data of the railway businesses shown in Fig. 5. The study results were reported as indicated below:

1) The major elements of RF, i.e. disaster characteristics and financial conditions, differ greatly among the railway businesses as shown in Fig. 9.

2) For storm and flood disasters in railway business, it is statistically proved that the number of losses in a fixed time interval conforms to Poisson distribution and the amount of loss per disaster conforms to the exponential distribution.

3) A ruin probability model for a railway business in case of storm and flood disasters has been proposed by applying the risk theory.

\section{(3) Necessity of analyzing storm and flood disaster} RF targeted multiple railway businesses

As described in Section 2.(1), storm and flood disasters, which account for about $90 \%$ of the damage caused by natural disasters, tend to increase and intensify over time. Accordingly, railway companies substantially require storm and flood disaster RF that is implemented objectively, scientifically, and quantitatively. The interview survey conducted in this

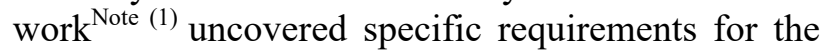
analysis of storm and flood RF targeted toward multiple-railway businesses. These needs are presented below:

1) Administrative agencies and railway trade associations want to study storm and flood disaster RF with targeting multiple railway businesses under their supervision.

2) These institutions also desire to study the storm and flood disaster RF that consists of multiple railway businesses who subscribe to group storm and flood insurance.

3) The companies that own multiple railway routes want to study the storm and flood disaster RF that will cover their entire railway routes.

4) Multiple railway businesses characterized by a capital relationship, such as a parent-subsidiary affiliation, want to study the storm and flood disaster RF for their affiliates as a whole for the purpose of consolidated accounts.

\section{(4) Basic stance of this study}

In cases wherein railway companies grapple with financial difficulties and have insufficient working capital to implement RF strategies against storm and flood disasters, a necessary requirement is a scientific method for evaluating multiple financing approaches, including the use of reserve funds and the acquisition of insurance. Additionally, the scale of disasters that occurred relatively frequently in the past should be estimated while considering the characteristics of disasters that affect the railway industry and the financial conditions of each railway business. To the best of our knowledge, only one study ${ }^{2}$ has put forward a scientific method underlain by a systematic and clear rationale for railway companies.

On the other hand, as described in Section 2.(3) above, there are a lot of needs in railway business to study storm and flood disaster RF with targeting multiple railway businesses. Accordingly, this study adopts an approach of estimating and studying financing, including utilization of additional procurable funds (e.g., insurance, subsidy) in next fiscal year or later as well as conditions of initial reserves through using mathematical statistics and data analysis.

The provisions of the Insurance Business Act in Japan specify a scientific basis for calculating the amount of damage caused by a large-scale natural disaster. For example, the Ministry of Finance's notice on Article 70 (2) of the Ordinance for Enforcement of the Insurance Business Act (1998) stipulates that an engineering model shall be used in principle and a model based on theoretical distribution that statistically processes the past results may be used for the natural disasters without any engineering model. The mathematical statistics model proposed in this study corresponds to the latter part of the stipulation.

\section{MODEL OF AGGREGATE LOSS CAUSED BY STORM AND FLOD DIS- ASTERS}

\section{(1) Model of aggregate loss caused by natural disasters}

We now consider aggregate loss caused by natural disasters which occur in a fixed time interval $[0, t](t$ $\geq 0$ ), typically one year, in multiple $(m)$ railway businesses based on the definitions in Ohori and Morichi $(2016)^{2}$.

a) Aggregate loss caused by natural disasters in a railway business

Suppose that random variable $S_{i t}$ denotes an aggregate loss caused by natural disasters which occur in a fixed time interval $[0, t](t \geq 0)$ in the $i$-th railway business $(i=1,2, \ldots, m)$. For this business, random 
variable $N_{i t}$ denotes the amount of losses caused by natural disasters that occur in $[0, t](t \geq 0)$, and random variable $X_{i j}$ denotes the amount of losses caused by the $j$-th natural disaster $\left(j=1,2, \ldots, N_{i t}\right)$.

Let us consider two assumptions. First, $\left\{X_{i j}\right\}_{j=1}^{\infty}(i$ $=1,2, \ldots, m)$ is assumed to be a sequence of independent and identically distributed random variables. Second, $N_{i t}$ is assumed to be independent of $\left\{X_{i j}\right\}_{j=1}^{\infty}$ $(i=1,2, \ldots, m)$. Then, random variable $S_{1}, S_{2}, \ldots, S_{m}$ are also independent of one another.

Based on the two assumptions, the aggregate loss is the sum of individual loss amounts with the understanding that $S_{i t}=0$ when $N_{i t}=0$ as shown below:

$$
S_{i t}=X_{i 1}+X_{i 2}+\cdots+X_{i N_{i t}} \quad(i=1,2, \cdots, m)
$$

b) Aggregate loss caused by natural disasters in multiple railway businesses

Random variable $N_{t}$ denotes the total number of losses caused by natural disasters that occur in a fixed time interval $[0, t](t \geq 0)$ in multiple $(m)$ railway businesses. On the assumptions mentioned in item a) of Section 3.(1), the formula is as follows:

$$
N_{t}=N_{1 t}+N_{2 t}+\cdots+N_{m t} .
$$

The aggregate loss caused by natural disasters that occur in a fixed time interval $[0, t](t \geq 0)$ in multiple $(m)$ railway businesses, $S_{t}$, is shown below, on the assumption mentioned in item a) of Section 3.(1):

$$
S_{t}=S_{1 t}+S_{2 t}+\cdots+S_{m t}=\sum_{i=1}^{m} \sum_{j=1}^{N_{i t}} X_{i j} .
$$

c) Annual aggregate loss caused by natural disasters in multiple railway businesses

It is considered desirable that the fixed time interval $[0, t](t \geq 0)$ should be one year in principle with taking account of the business customs in railway business, legal system for accounting and insurance, data management and others, all of which are typically on one year based. Therefore, we usually consider one year as a fixed time interval $[0, t](t \geq 0)$ and omit subscript $t$. Equations (1) to (3) are then converted into equations (4) to (6), respectively:

$$
\begin{aligned}
& S_{i}=X_{i 1}+X_{i 2}+\cdots+X_{i N_{i}} \quad(i=1,2, \cdots, m) \\
& N=N_{1}+N_{2}+\cdots+N_{m} \\
& S=S_{1}+S_{2}+\cdots+S_{m}=\sum_{i=1}^{m} \sum_{j=1}^{N_{i}} X_{i j} .
\end{aligned}
$$

\section{(2) Aggregate loss caused by storm and flood dis- asters in a railway business}

In this section, we focus on storm and flood disasters as natural disaster in Section 4.(1). According to the findings of Ohori and Morichi $(2016)^{2}$, the distribution of the number of losses caused by storm and flood disasters which occur in a year conforms to Poisson distribution and the amount of each loss is exponentially distributed. On the basis of this findings, we can express the aggregate loss caused by storm and flood disasters which occur in a fixed time interval in multiple $(m)$ railway businesses concretely as follows.

a) Annual number of losses caused by storm and flood disasters in a railway business

Random variable $N_{i}(i=1,2, \ldots, m)$ represents the number of losses caused by storm and flood disasters that occur in a year in the $i$-th railway business, and conforms to Poisson distribution with parameter $\lambda_{i}$, the probability function of whith is given by the following formula:

$$
P\left(N_{i}=n\right)=e^{-\lambda_{i}} \frac{\lambda_{i}^{n}}{n !}\left(\begin{array}{c}
n=0,1,2, \cdots \\
i=1,2, \cdots, m
\end{array}\right) .
$$

The moment generating function is

$$
M_{N_{i}}(r)=\exp \left\{\lambda_{i}\left(e^{r}-1\right)\right\} \quad(i=1,2, \cdots, m) .
$$

Hence, it follows that

$$
E\left(N_{i}\right)=V\left(N_{i}\right)=\lambda_{i} \quad(i=1,2, \cdots, m) .
$$

b) Amount of each loss caused by a storm and flood disaster in a railway business

Random variable $X_{i}(i=1,2, \ldots, m)$ denotes the amount of each loss caused by storm and flood disaster in the $i$-th railway business. It is exponentially distributed with parameter $\mu_{i}$, whose density function is given by the following formula:

$$
f_{X_{i}}(x)=\frac{1}{\mu_{i}} \exp \left(-\frac{1}{\mu_{i}} x\right) \quad(x \geq 0, i=1,2, \cdots, m) .
$$

The distribution function is given by the following formula:

$$
F_{X_{i}}(x)=1-\exp \left(-\frac{1}{\mu_{i}} x\right) \quad(x \geq 0, i=1,2, \cdots, m) .
$$

Therefore,

$$
\begin{aligned}
& E\left(X_{i}\right)=\mu_{i} \quad(i=1,2, \cdots, m), \\
& V\left(X_{i}\right)=\mu_{i}^{2} \quad(i=1,2, \cdots, m) .
\end{aligned}
$$

c) Annual aggregate loss caused by storm and flood disasters in a railway business

Random variable $S_{i}(i=1,2, \ldots, m)$ denotes the aggregate loss caused by storm and flood disasters which occur in a year in the $i$-th railway business. $S_{i}$ can be calculated with using conditional expectation arguments and the results in items a) and b) of Section 3.(2) as follows:

$$
\begin{aligned}
E\left(S_{i}\right) & =E\left(N_{i}\right) E\left(X_{i}\right)=\lambda_{i} \mu_{i} \quad(i=1,2, \cdots, m) \\
V\left(S_{i}\right) & =E\left(N_{i}\right) V\left(X_{i}\right)+V\left(N_{i}\right) E\left(X_{i}\right)^{2} \\
& =2 \lambda_{i} \mu_{i}^{2} \quad(i=1,2, \cdots, m) \\
M_{S_{i}}(r) & =M_{N_{i}}\left[\log M_{X_{i}}(r)\right]=\exp \left\{\lambda_{i}\left(M_{X_{i}}(r)-1\right)\right\} \\
& =\exp \left(\frac{\lambda_{i} \mu_{i} r}{1-\mu_{i} r}\right) \quad(i=1,2, \cdots, m) .
\end{aligned}
$$


(3) Annual aggregate loss caused by storm and flood disasters in multiple railway businesses

In this section, we consider the case of multiple $(\mathrm{m})$ railway businesses instead of a railway business in Section 4.(2).

a) Annual number of losses caused by storm and flood disasters in multiple railway businesses

Random variable $N$ denotes the number of losses caused by storm and flood disasters that occur in a year in multiple $(m)$ railway businesses. On the assumption mentioned in item a) of Section 4.(1), $N$ is expressed by formula (5). On the basis of the independence of $N_{i}(i=1,2, \ldots, m)$ and the reproductive property of Poisson distribution, $N$ conforms to the distribution with the following parameter:

$$
\lambda=\lambda_{1}+\lambda_{2}+\cdots+\lambda_{m} \text {. }
$$

The probability function is given by

$$
P(N=n)=e^{-\lambda} \frac{\lambda^{n}}{n !} \quad(n=0,1,2, \ldots) .
$$

The moment generating function is

$$
M_{N}(r)=\exp \left\{\lambda\left(e^{r}-1\right)\right\} \text {. }
$$

Accordingly,

$$
E(N)=V(N)=\lambda \text {. }
$$

b) Amount of each loss caused by a storm and flood disaster in multiple railway businesses

The amount of each loss caused by a storm and flood disaster in multiple $(m)$ railway businesses is the random variable $X_{i j}$ denoted by formula (6). For simplicity, we now write a representative symbol of $X_{i j}$ in $X$.

With the assumptions stated in item a) of Section 3.(1) and formulas (8), (16), and (17) as basis, the moment generating function of $S$ expressed by formula (6) is as follows:

$$
\begin{aligned}
M_{S}(r) & =\prod_{i=1}^{m} M_{S_{i}}(r)=\prod_{i=1}^{m} M_{N_{i}}\left[\log M_{X_{i}}(r)\right] \\
& =\exp \left\{\lambda\left(\sum_{i=1}^{m} \frac{\lambda_{i}}{\lambda} M_{X_{i}}(r)-1\right)\right\} .
\end{aligned}
$$

On the other hand, by formulas (5), (6), (16), and (17), the moment generating function of $S$ can also be expressed as follows:

$$
M_{S}(r)=\exp \left\{\lambda\left(M_{X}(r)-1\right)\right\} .
$$

Because equation (21) is the same as equation (22) and because of the uniqueness property of moment generating functions, it follows that:

$$
M_{X}(r)=\sum_{i=1}^{m} \frac{\lambda_{i}}{\lambda} M_{X_{i}}(r) \text {. }
$$

Therefore, the distribution function of $X$ is given by the following formula:

$$
F_{X}(x)=\sum_{i=1}^{m} \frac{\lambda_{i}}{\lambda} F_{X_{i}}(x) \quad(x \geq 0) .
$$

It means that the distribution of $X$ is compound Poisson by the result mentioned in item a) of 3.(3), with Poisson parameter derived from formula (17). From formula (11), formula (24) can be written as follows:

$$
\begin{aligned}
F_{X}(x) & =\sum_{i=1}^{m} \frac{\lambda_{i}}{\lambda}\left\{1-\exp \left(-\frac{1}{\mu_{i}} x\right)\right\} \\
& =1-\sum_{i=1}^{m} \frac{\lambda_{i}}{\lambda} \exp \left(-\frac{1}{\mu_{i}} x\right) \quad(x \geq 0) .
\end{aligned}
$$

Thus, the density function of $X$ is described as

$$
f_{X}(x)=\sum_{i=1}^{m} \frac{\lambda_{i}}{\lambda}\left\{\frac{1}{\mu_{i}} \exp \left(-\frac{1}{\mu_{i}} x\right)\right\} \quad(x \geq 0) .
$$

The moment generating function of $X$ is as follows:

$$
M_{X}(r)=\sum_{i=1}^{m} \frac{\lambda_{i}}{\lambda} \frac{1}{1-\mu_{i} r} .
$$

Hence, it follows that:

$$
\begin{aligned}
& \mu=E(X)=M_{X}^{(1)}(0)=\sum_{i=1}^{m} \frac{\lambda_{i}}{\lambda} \mu_{i} \\
& E\left(X^{k}\right)=M_{X}^{(k)}(0)=\sum_{i=1}^{m} \frac{\lambda_{i}}{\lambda} k ! \mu_{i}^{k} .
\end{aligned}
$$

c) Annual aggregate loss caused by storm and flood disasters in multiple railway businesses

The aggregate loss caused by storm and flood disasters in multiple $(m)$ railway businesses is random variable $S$ denoted by formula (6). On the assumption mentioned in item a) of Section 3.(1) and based on formulas (6), (14), and (15), the expectation and variance of $S$ are as follows:

$$
\begin{aligned}
& E(S)=\sum_{i=1}^{m} E\left(S_{i}\right)=\sum_{i=1}^{m} \lambda_{i} \mu_{i} \\
& V(S)=\sum_{i=1}^{m} V\left(S_{i}\right)=2 \sum_{i=1}^{m} \lambda_{i} \mu_{i}^{2} .
\end{aligned}
$$

\section{RUIN PROBABILITY MODEL IN MULTIPLE RAILWAY BUSINESSES}

\section{(1) Ruin probability model in a railway business}

Based on the Ohori and Morichi (2016) ${ }^{2)}$ application of the Cramér-Lundberg model ${ }^{20)-22)}$, the surplus process of the $i$-th railway business, denoted by $\left\{U_{i t}\right\}_{t \geq 0}$, is described as follows:

$$
U_{i t}:=u_{i 0}+P_{i t}-S_{i t} \quad(i=1,2, \cdots, m),
$$

where

$m$ : the total number of railway businesses,

$u_{i 0}$ : the initial reserves of the $i$-th railway business at the beginning of a fixed time interval $[0, t](t \geq 0)$, $u_{i 0} \geq 0$ (e.g., internal reserves, fund balance),

$P_{i t}$ : the additional procurable funds within a fixed time interval $[0, t]$ in the $i$-th railway business (e.g., insurance money, subsidy),

$S_{i t}$ : the aggregate loss caused by natural disasters that 
occur in a fixed time interval $[0, t]$ in the $i$-th railway business.

Let us now consider two assumptions regarding the financial independence of each railway business. First, each $u_{i 0}(i=1,2, \ldots, m)$ is assumed to be independent mutually. Second, $P_{i t}(i=1,2, \ldots, m)$ is also assumed to be independent mutually.

Because disaster characteristics differ across railway businesses, $P_{i t}(i=1,2, \ldots, m)$ corresponds oneto-one with its $E\left(S_{i t}\right)$ and $\theta_{i}$ as follows:

$$
\begin{aligned}
& c_{i}:=\left(1+\theta_{i}\right) E\left(S_{i}\right) \quad(i=1,2, \cdots, m) \\
& P_{i t}:=c_{i} t=\left(1+\theta_{i}\right) E\left(S_{i}\right) t \quad(i=1,2, \cdots, m)
\end{aligned}
$$

where

$c_{i}$ : the additional procurable funds within a time unit of typically one year in the $i$-th railway business,

$\theta_{i}$ : the safety loading factor of additional procurable fund for an expected aggregate loss in the $i$-th railway business, $\theta_{i} \geq 0$.

Thus, $U_{i}$ is described as follows:

$$
U_{i t}=u_{i 0}+\left(1+\theta_{i}\right) E\left(S_{i}\right) t-S_{i t} \quad(i=1,2, \cdots, m) .
$$

The interest of this research is now directed to the probability of ruin due to disasters. Focusing on $u_{i 0}$ and $\theta_{i}$, which are the main factors of RF, the ruin probability of RF for the $i$-th railway business, denoted by $\varepsilon_{t}\left(u_{i 0}, \theta_{i}\right)$, is written as

$$
\begin{aligned}
& \varepsilon_{t}\left(u_{i 0}, \theta_{i}\right):=P\left(U_{i t}<0\right)= \\
& P\left[u_{i 0}+\left(1+\theta_{i}\right) E\left(S_{i}\right) t-S_{i t}<0\right] \quad(i=1,2, \cdots, m) .
\end{aligned}
$$

\section{(2) Ruin probability model in multiple railway businesses}

When multiple $(\mathrm{m})$ railway businesses jointly manage and use funds for recovery from natural disasters, the surplus process of multiple $(m)$ railway businesses, denoted by $\left\{U_{t}\right\}_{t \geq 0}$, is described as follows:

$$
U_{t}:=u_{0}+P_{t}-S_{t}
$$

where

$m$ : the total number of railway businesses,

$u_{0}$ : the initial reserves of multiple $(\mathrm{m})$ railway businesses at the beginning of a fixed time interval $[0$, $t](t \geq 0), u_{0} \geq 0$ (e.g., total of each internal reserve, fund balance),

$P_{t}$ : the additional procurable fund within a fixed time interval $[0, t]$ in multiple $(m)$ railway business (e.g., total of each insurance, subsidy),

$S_{t}$ : the aggregate loss caused by natural disasters that occur in a fixed time interval $[0, t]$ in multiple $(m)$ railway businesses.

On the assumption in Section 4.(1), it follows that

$$
u_{0}=\sum_{i=1}^{m} u_{i 0}
$$

$$
P_{t}=\sum_{i=1}^{m} P_{i t} .
$$

Thus, from formulas (3), (32), and (35), formula (37) is described as follows:

$$
\begin{aligned}
U_{t} & =\sum_{i=1}^{m} U_{i t}=\sum_{i=1}^{m}\left(u_{i 0}+P_{i t}-S_{i t}\right) \\
& =\sum_{i=1}^{m}\left\{u_{i 0}+\left(1+\theta_{i}\right) E\left(S_{i}\right) t-S_{i t}\right\} .
\end{aligned}
$$

Correspondingly, focusing on $u_{i 0}$ and $\theta_{i}$, the ruin probability in multiple $(m)$ railway businesses, denoted by $\varepsilon_{t}\left(u_{i 0}, \theta_{i} ; i=1,2, \ldots, m\right)$, can be written as follows:

$$
\begin{aligned}
& \varepsilon_{t}(\left.u_{i 0}, \theta_{i} ; i=1,2, \cdots, m\right):=P\left(U_{t}<0\right) \\
& \quad=P\left[\sum_{i=1}^{m}\left\{u_{i 0}+\left(1+\theta_{i}\right) E\left(S_{i}\right) t-S_{i t}\right\}<0\right] .
\end{aligned}
$$

As described in item c) of Section 3.(1), we consider one year as a fixed time interval $[0, t](t \geq 0)$ and omit subscript $t$. Then, formulas (35), (39), (40), and (41) are indicated as formulas (42), (43), (44), and (45) respectively:

$$
\begin{aligned}
U_{i} & =u_{i 0}+c_{i}-S_{i} \\
& =u_{i 0}+\left(1+\theta_{i}\right) E\left(S_{i}\right)-S_{i} \quad(i=1,2, \cdots, m) \\
P & =\sum_{i=1}^{m} P_{i}=c=\sum_{i=1}^{m} c_{i}=\sum_{i=1}^{m}\left(1+\theta_{i}\right) E\left(S_{i}\right) \\
U & =u_{0}+P-S=\sum_{i=1}^{m} U_{i}=\sum_{i=1}^{m}\left(u_{i 0}+P_{i}-S_{i}\right) \\
& =\sum_{i=1}^{m}\left\{u_{i 0}+\left(1+\theta_{i}\right) E\left(S_{i}\right)-S_{i}\right\} \\
\varepsilon & :=\varepsilon\left(u_{0}, \theta_{i} ; i=1,2, \cdots, m\right)=P(U<0) \\
& =P\left[\sum_{i=1}^{m}\left\{u_{i 0}+\left(1+\theta_{i}\right) E\left(S_{i}\right)-S_{i}\right\}<0\right] .
\end{aligned}
$$

\section{(3) Surplus immediately after ruin and theorem on ruin probability}

It is difficult to determine the ruin probability rigorously in many cases. Also, calculation of formulas (41) and (45) is often difficult, because the determination of probability distribution of $U_{t}$ is difficult in itself. Thus, we consider a method for calculating the ruin probability as another approach, which focuses on the surplus immediately after ruin for this study. Let us now introduce the surplus immediately after ruin and theorem on the ruin probability for a railway business in item a) of Section 4.(3) and make an extension for multiple railway businesses in item $\mathbf{b}$ ) of Section 4.(3). 
a) Surplus immediately after ruin and ruin probability in a railway business

Given the ruin as a state of $U_{i t}<0$ in the $i$-th $(i=1$, $2, \ldots, m)$ railway business is defined in Section 4.(1), we denote the time of ruin by continuous random variable $T_{i}$ and define it by

$$
T_{i}:=\min \left\{t \mid U_{i t}<0\right\}
$$

with $T_{i}=\infty$ if $U_{i t} \geq 0$ for all $t>0$. If the ruin occurs and the probability $G\left(u_{i 0}, y\right)$ that surplus $\left(-U_{i t}\right)$ immediately after ruin becomes $y(y \geq 0)$ or more is defined in formula (47):

$$
G\left(u_{i 0}, y\right):=P\left(T<\infty \cap-U_{i T}>y\right) .
$$

At this time, the following formula (49) can be established from formulas (41) and (47):

$$
\varepsilon_{t}\left(u_{i 0}, \theta_{i}\right)=G\left(u_{i 0}, 0\right)
$$

On the other hand, the function $G\left(u_{i 0}, y\right)$ defined as (47) satisfies the equation ${ }^{21)}$

$$
\begin{aligned}
& \frac{\partial}{\partial u_{i 0}} G\left(u_{i 0}, y\right)=\frac{\lambda_{i}}{c_{i}} \times \\
& \left\{G\left(u_{i 0}, y\right)-\int_{0}^{u_{i 0}} G\left(u_{i 0}-x, y\right) d F_{X_{i}}(x)-\int_{u_{i 0}+y}^{\infty} d F_{X_{i}}(x)\right\} .
\end{aligned}
$$

By using the theorem on equation (49), the following equations are generally formed for $G\left(u_{i 0}, y\right)(i=1,2$, $\ldots, m)^{21)}$.

$$
\begin{aligned}
& G(\infty, y)=0 \\
& G(0, y)=\frac{\lambda_{i}}{c_{i}} \int_{y}^{\infty}\left\{1-F_{X_{i}}(x)\right\} d x \\
& G(0,0)=\frac{\lambda_{i}}{c_{i}} E\left(X_{i}\right)=\frac{1}{1+\theta_{i}} .
\end{aligned}
$$

Now, if the initial reserve $u_{i 0}(i=1,2, \ldots, m)$ is 0 , the distribution function $F_{Y i}(y)$ of $Y_{i}$ can be expressed in the following function (53) with assuming the random variable as $Y_{i}$, which represents the surplus immediately after ruin:

$$
\begin{aligned}
F_{Y_{i}}(y) & =P\left(Y_{i}=-U_{i T} \leq y \mid u_{i 0}=0 \cap T<\infty\right) \\
& =1-P\left(-U_{i T}>y \mid u_{i 0}=0 \cap T<\infty\right) \\
& =1-\frac{G(0, y)}{G(0,0)}=1-\frac{1}{\mu_{i}} \int_{y}^{\infty}\left\{1-F_{X_{i}}(x)\right\} d x \\
& =\frac{1}{\mu_{i}} \int_{0}^{y}\left\{1-F_{X_{i}}(x)\right\} d x \quad(i=1,2, \cdots, m)
\end{aligned}
$$

b) Surplus immediately after ruin and ruin probability in multiple railway businesses

The following formula can also be established as seen in item a) of Section 4.(3) for disaster restoration of multiple $(m)$ railway businesses defined in Section 4.(2). Given the ruin as a state of $U_{t}<0$, we denote the time of ruin by continuous random variable $T$ and define it by

$$
T:=\min \left\{t \mid U_{t}<0\right\}
$$

with $T=\infty$ if $U_{t} \geq 0$ for all $t>0$. If the ruin occurs and the probability $G\left(u_{0}, y\right)$ that the surplus $\left(-U_{t}\right)$ immediately after ruin becomes $y(y \geq 0)$ or more is defined in formula (55):

$$
G\left(u_{0}, y\right):=P\left(T<\infty \cap-U_{T}>y\right) .
$$

At this point, the following formula is established from formulas (38), (41), and (55):

$$
\varepsilon_{t}\left(u_{i 0}, \theta_{i} ; i=1,2, \cdots, m\right)=G\left(u_{0}, 0\right) .
$$

For $G\left(u_{0}, y\right)$ as well, the following equations are established, as is the case discussed item a) of Section 4.(3):

$$
\begin{aligned}
& G(\infty, y)=0 \\
& G(0, y)=\frac{\lambda}{c} \int_{y}^{\infty}\left\{1-F_{X}(x)\right\} d x \\
& G(0,0)=\frac{\lambda}{c} E(X) .
\end{aligned}
$$

Now, the initial reserve $u_{0}$ is 0 , the distribution function $F_{Y}(y)$ of $Y$ can be expressed as is the case with formula (53) with assuming the random variable as $Y$, which represents the surplus immediately after ruin:

$$
F_{Y}(y)=\frac{1}{\mu} \int_{0}^{y}\left\{1-F_{X}(x)\right\} d x .
$$

Here, $F_{X}(x)$ is shown as seen in formula (25).

Conversely, the probability that ruin never occurs starting from initial surplus is known as the survival probability. The distribution function for a fixed time interval $[0, t]$ is defined in the following formula:

$$
\begin{aligned}
\varphi_{t}\left(u_{i 0}, \theta_{i} ; i\right. & =1,2, \cdots, m):=P\left(U_{t} \geq 0\right) \\
& =1-\varepsilon_{t}\left(u_{i 0}, \theta_{i} ; i=1,2, \cdots, m\right) .
\end{aligned}
$$

The following formula (62) is established from the theorem on survival probability in the CramérLundberg model ${ }^{21}$.

$$
\begin{aligned}
& \varphi_{t}\left(u_{i 0}, \theta_{i} ; i=1,2, \cdots, m\right) \\
& =\sum_{k=0}^{\infty}\{1-G(0,0)\} G(0,0)^{k} P\left(Y_{1}+\cdots+Y_{k} \leq u_{0}\right)
\end{aligned}
$$

where, $Y_{j}(j=1,2, \ldots, k)$ conforms to the same distribution reflected in the distribution function in formula (60) in a mutually independent manner. Accordingly, the ruin probability $\varepsilon_{t}$ can be expressed by formulas (61) and (62) as shown below:

$$
\begin{aligned}
& \varepsilon_{t}\left(u_{i 0}, \theta_{i} ; i=1,2, \cdots, m\right)= \\
& 1-\sum_{k=0}^{\infty}\{1-G(0,0)\} G(0,0)^{k} P\left(Y_{1}+\cdots+Y_{k} \leq u_{0}\right) .
\end{aligned}
$$

\section{(4) Calculation formulas of ruin probability in multiple railway businesses}

By using the definitions and the calculation formulas mentioned above, we can derive the following theorems on ruin probability for storm and flood disasters in the case that the revenue and cost for disaster 
restoration of multiple $(\mathrm{m})$ railway businesses are jointly managed.

\section{a) Ruin probability if each safety loading factor is equal}

Theorem 1: If the total initial reserve is $u_{0}$ and each safety loading factor $\theta_{i}(i=1,2, \ldots, m)$ of additional procurable funds for an expected aggregate loss in the $i$-th railway business is equal to $\theta(\theta \geq 0)$ in the ruin probability model for storm and flood disasters described in Sections 3.(3) and 4.(2), the ruin probability $\varepsilon$ for aggregate loss caused by storm and flood disasters occurred in a fixed time interval $[0,1]$ can be expressed in the following equation:

$$
\begin{aligned}
& \varepsilon\left(u_{i 0}, \theta_{i}=\theta ; i=1,2, \cdots, m\right) \\
& \quad=\sum_{i=1}^{m} \frac{\lambda_{i} \mu_{i}}{\lambda \mu}\left\{\frac{1}{1+\theta} \exp \left(-\frac{\theta}{(1+\theta) \mu_{i}} u_{0}\right)\right\} .
\end{aligned}
$$

[Proof] As described in item b) of Section 4.(3), we put focus on the surplus immediately after ruin in multiple $(m)$ railway businesses for disaster restoration and present that formula (63) turns into equation (64).

In case that $t=1$ and $\theta_{i}=\theta(i=1,2, \ldots, \mathrm{m})$ in formula (62), formulas (28) and (43) are substituted into formula (59) as follows:

$$
G(0,0)=\frac{1}{1+\theta} .
$$

Then, formula (65) is substituted into formula (62), the following formula is established:

$$
\begin{aligned}
\varphi & \left(u_{i 0}, \theta_{i}=\theta ; i=1,2, \cdots, m\right) \\
& =\sum_{k=0}^{\infty} \frac{\theta}{1+\theta}\left(\frac{1}{1+\theta}\right)^{k} P\left(Y_{1}+\cdots+Y_{k} \leq u_{0}\right) .
\end{aligned}
$$

On the other hand, formula (60) can be transformed by formula (25) as shown below:

$$
F_{Y}(y)=\sum_{i=1}^{m} \frac{\lambda_{i} \mu_{i}}{\lambda \mu}\left\{1-\exp \left(-\frac{1}{\mu_{i}} y\right)\right\} \quad(y \geq 0) .
$$

It indicates that formula (67) represents a mixed distribution which is obtained by weighting average exponential distribution to which the amount of loss $X_{i}$ $(i=1,2, \ldots, m)$ conforms. And, $Y_{j}(j=1,2, \ldots, k)$ in formula (66) conforms to the same distribution which is expressed by the distribution function in formula (67) in a mutually independent manner. The exponential distribution is a type of gamma distribution, whose reproductive property yields the following formula:

$$
\begin{aligned}
& P\left(Y_{1}+\cdots+Y_{k} \leq u_{0}\right) \\
& =\sum_{i=1}^{m} \frac{\lambda_{i} \mu_{i}}{\lambda \mu} \int_{0}^{u_{0}} \frac{1}{\mu_{i}(k-1) !}\left(\frac{y}{\mu_{i}}\right)^{k-1} \exp \left(-\frac{1}{\mu_{i}} y\right) d y .
\end{aligned}
$$

Thus, if formula (68) is substituted into formula (66), the following transformation is realized:

$$
\begin{aligned}
& \varphi\left(u_{i 0}, \theta_{i}=\theta ; i=1,2, \cdots, m\right) \\
& =\frac{\theta}{1+\theta}+\sum_{i=1}^{m} \frac{\lambda_{i} \mu_{i}}{\lambda \mu} \frac{\theta}{(1+\theta)^{2} \mu_{i}} \times \\
& \int_{0}^{u_{0}} \sum_{k=1}^{\infty} \frac{1}{(k-1) !}\left\{\frac{y}{(1+\theta) \mu_{i}}\right\}^{k-1} \exp \left(-\frac{1}{\mu_{i}} y\right) d y \\
& =\frac{\theta}{1+\theta}+\sum_{i=1}^{m} \frac{\lambda_{i} \mu_{i}}{\lambda \mu} \frac{\theta}{(1+\theta)^{2} \mu_{i}} \int_{0}^{u_{0}} \exp \left\{-\frac{\theta}{(1+\theta) \mu_{i}} y\right\} d y \\
& =1-\sum_{i=1}^{m} \frac{\lambda_{i} \mu_{i}}{\lambda \mu} \frac{1}{1+\theta}\left\{1-\exp \left(-\frac{\theta}{\lambda_{i} \mu_{i}}\left\{\frac{1}{1+\theta} \exp \left(-\frac{\theta}{(1+\theta) \mu_{i}}\right)\right\}\right.\right.
\end{aligned}
$$

Therefore, if formula (69) is substituted into formula (61), equation (64) is derived and the proof is completed. Q.E.D.

Corollary 1: If the initial reserve is $u_{0}$ and the safety loading factor of additional procurable funds for an expected aggregate loss in a railway business is $\theta(\theta$ $\geq 0$ ) in the ruin probability model for storm and flood disasters described in Sections 3.(2) and 4.(1), the ruin probability $\varepsilon$ for aggregate loss caused by storm and flood disasters occurred in a fixed time interval $[0,1]$ can be expressed in the following equation:

$$
\varepsilon\left(u_{0}, \theta\right)=\frac{1}{1+\theta} \exp \left\{-\frac{\theta}{(1+\theta) \mu} u_{0}\right\} .
$$

[Proof] As a case of $m=1$ in Theorem 1, the equation (70) is immediately shown with using formula (64) . Q.E.D.

Formula (70) is consistent with the ruin probability formula proposed by Ohori and Morichi $(2016)^{2)}$. It means that these calculation formulas are consistent mutually, even though the proof methods are different. Furthermore, comparing formula (64) with formula (70), it is also found that formula (64) is obtained by weighting average storm and flood disaster risks in multiple $(m)$ railway businesses.

\section{b) Ruin probability if each safety loading factor is optional}

Theorem 2: If the total initial reserve is $u_{0}$ and each safety loading factor of additional procurable funds for an expected aggregate loss in the $i$-th railway business is $\theta_{i}\left(\theta_{i} \geq 0, i=1,2, \ldots, m\right)$ in the ruin probability model for storm and flood disasters described in Sections 3.(3) and 4.(2), the ruin probability $\varepsilon$ for aggregate loss caused by storm and flood disasters occurred in a fixed time interval $[0,1]$ can be expressed in equations (71) and (72): 


$$
\begin{aligned}
& \varepsilon\left(u_{i 0}, \theta_{i}=\theta ; i=1,2, \cdots, m\right) \\
& =\sum_{i=1}^{m} \frac{\lambda_{i} \mu_{i}}{\lambda \mu}\left\{G(0,0) \cdot \exp \left(-(1-G(0,0)) \frac{u_{0}}{\mu_{i}}\right)\right\} \quad \\
& = \\
& \sum_{i=1}^{m} \frac{\lambda_{i} \mu_{i}}{\lambda \mu}\left\{\left(\frac{\sum_{i=1}^{m} \lambda_{i} \mu_{i}}{\sum_{i=1}^{m}\left(1+\theta_{i}\right) \lambda_{i} \mu_{i}}\right) \exp \left(-\left(\frac{\sum_{i=1}^{m} \theta_{i} \lambda_{i} \mu_{i}}{\sum_{i=1}^{m}\left(1+\theta_{i}\right) \lambda_{i} \mu_{i}}\right) \frac{u_{0}}{\mu_{i}}\right)\right\}
\end{aligned}
$$

[Proof] The following formula is derived with assuming $t=1$ and $\theta_{i}(i=1,2, \ldots, m)$ in formula (61):

$$
\varepsilon\left(u_{i 0}, \theta_{i} ; i=1,2, \cdots, m\right)=1-\varphi\left(u_{i 0}, \theta_{i} ; i=1,2, \cdots, m\right) \text {. }
$$

Based on formula (62), the following formula is established:

$$
\begin{aligned}
& \varphi\left(u_{i 0}, \theta_{i} ; i=1,2, \cdots, m\right) \\
= & \sum_{k=0}^{\infty}\{1-G(0,0)\} G(0,0)^{k} P\left(Y_{1}+\cdots+Y_{k} \leq u_{0}\right) .
\end{aligned}
$$

Here, $G(0,0)$ is shown below by using formulas (28), (43), and (59):

$$
G(0,0)=\frac{\sum_{i=1}^{m} \lambda_{i} \mu_{i}}{\sum_{i=1}^{m}\left(1+\theta_{i}\right) \lambda_{i} \mu_{i}} .
$$

Accordingly, the following formula (76) can also be established:

$$
1-G(0,0)=\frac{\sum_{i=1}^{m} \theta_{i} \lambda_{i} \mu_{i}}{\sum_{i=1}^{m}\left(1+\theta_{i}\right) \lambda_{i} \mu_{i}} .
$$

Given that formula (68) is also established in this proposition, formula (74) can be converted into the following formula with $G(0,0)$ simply indicated as $G$ :

$$
\begin{aligned}
& \varphi\left(u_{i 0}, \theta_{i}=\theta ; i=1,2, \cdots, m\right) \\
& =(1-G)+\sum_{k=1}^{\infty}(1-G) G^{k} P\left(Y_{1}+\cdots+Y_{k} \leq u_{0}\right) \\
& =(1-G)+\sum_{i=1}^{m} \frac{\lambda_{i} \mu_{i}}{\lambda \mu} \frac{(1-G) G}{\mu_{i}} \times \\
& \quad \int_{0}^{u_{0}} \sum_{k=1}^{\infty} \frac{1}{(k-1) !}\left(\frac{G y}{\mu_{i}}\right)^{k-1} \exp \left(-\frac{1}{\mu_{i}} y\right) d y \\
& =(1-G)+\sum_{i=1}^{m} \frac{\lambda_{i} \mu_{i}}{\lambda \mu} \frac{(1-G) G}{\mu_{i}} \int_{0}^{u_{0}} \exp \left(-\frac{1-G}{\mu_{i}} y\right) d y \\
& =(1-G)+\sum_{i=1}^{m} \frac{\lambda_{i} \mu_{i}}{\lambda \mu} G\left\{1-\exp \left(-\frac{1-G}{\mu_{i}} u_{0}\right)\right\}
\end{aligned}
$$

$$
=1-\sum_{i=1}^{m} \frac{\lambda_{i} \mu_{i}}{\lambda \mu} G\left\{\exp \left(-\frac{1-G}{\mu_{i}} u_{0}\right)\right\} .
$$

Consequently, equation (71) is established when formula (77) is substituted into formula (73). Furthermore, substituting formulas (75) and (76) into equation (71) yields equation (72), and the proof is successfully completed. Q.E.D.

\section{CASE STUDIES ON STORMS AND FLOODS EXPERIENCED BY IN MUL- TIPLE RAILWAY BUSINESSES}

\section{(1) Railway companies analyzed}

In order to validate the methodology proposed in Sections 3 and 4, the ruin probability model put forward in this research is analyzed on the basis of data collected on the third-sector railway companies shown in Fig. 5. The data reflect the actual losses caused by storm and flood disasters, as well as financial data over the past 22 years from FY1991 to FY2012. These data were provided by the Third-Sector Railway Companies Association ${ }^{31)}$ and the Railway Bureau of the Ministry of Land, Infrastructure, Transport and Tourism (MLIT).

Third-sector railway companies are joint publicly and privately financed railways. Local governments in Japan can own shares in corporations and do own shares in third-sector railway companies. Many thirdsector railways are located in rural areas, and the companies operating on these railways were taken over mainly from the unremunerative local lines of Japan National Railways (currently JR companies) and are managed through investments from local governments. Although a large number of these railways are unprofitable lines, they are still necessary to the surrounding communities.

First, actual data on third-sector railways are analyzed primarily for the following reasons:

1) Third-sector railway companies are distributed nationally (Fig. 5), and are therefore suitable subjects of investigations into factors that characterize nationwide tendencies related to storm and flood occurrence, including diverse determinants such as climate and topography.

2) Because almost no anti-disaster measure constructions have been implemented by the third-sector railway companies, the characteristics of the statistical population related to storm and flood damages remain almost the same over time $\mathrm{e}^{\text {Note (1). }}$

3) Most third-sector railway companies have been covered by continuous natural disaster insurance for civil engineering structures ${ }^{31)}$. Therefore, historical data on disasters, such as insurance payments, are precisely recorded. 
4) All actual data on public financial support in subsidy systems for the restoration of railway companies are recorded by the MLIT.

5) RF strategies against storms and floods is becoming increasingly important to railway businesses suffering from financial difficulties, especially third-sector railway companies.

Second, eleven railway companies (Fig. 6) are subjected to the analysis. The reasons for this selection include long-term data accumulation, retention of nationwide diversity in terms of landforms and climate conditions, easy understanding of disaster characteristics due to the availability of large amounts of data on the actual damage by storm and flood disasters, and the differences in financial conditions of the respective railway companies.

Third, in this sampling, the difference in initial reserves is considered on the financing situation. The initial reserves of the companies reflect the smallest to largest variations nationwide.

Fourth, the difference in the ruin probability is also considered in the sampling. Figure 12 shows that the calculated values of the ruin probability in FY2013 in storm and flood disaster RF for the railway companies based on the calculation proposed by Ohori and Morichi (2016) $)^{2)}$.

\section{(2) Case studies on ruin probability in a railway business}

The ruin probability of RF for a railway business can be calculated by means of Corollary 1 . It can be computed on the basis of combined initial reserves and additional procurable funds, as shown in formula (70).

For example, if the fund balance (actual amount) is set as initial reserves at the beginning of FY2013, the ruin probability at the end of FY2013 can be calculated as indicated in Fig. 7 for D railway company and Fig. 8 for G railway company. Both calculations are based on disaster data spanning the past 22 years. Comparing Fig. 7 with Fig. 8, it is found that the graphs in these figures reflect the disaster characteristics (actual losses) and RF situations (initial reserves and additional procurable funds) of the two railway companies.

The disaster characteristics and RF situations are greatly different for each railway company in many cases. This feature is also identified by the hearing survey, in addition to the relevant data. The disaster characteristics are diversified depending on climate conditions, landforms and structures, and financial conditions of each railway company are also highly different because of variances in corporate management policy and railway transport demand. Actual examples of the effects of such differences in disaster characteristics and RF situations on ruin probability

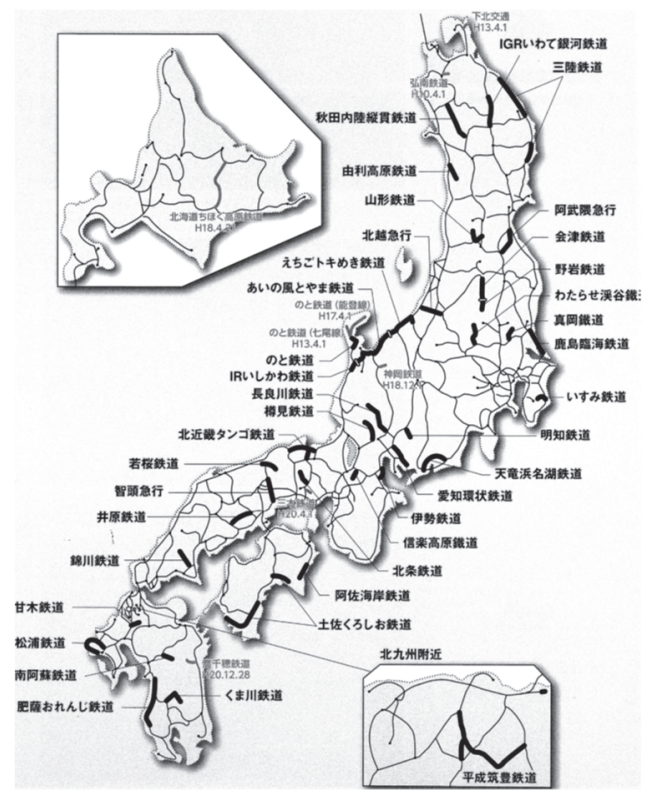

Fig.5 Locations of third-sector railway companies in Japan ${ }^{31)}$.

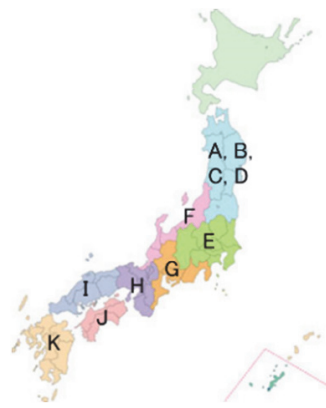

Fig.6 The 11 railway companies selected for the analysis.

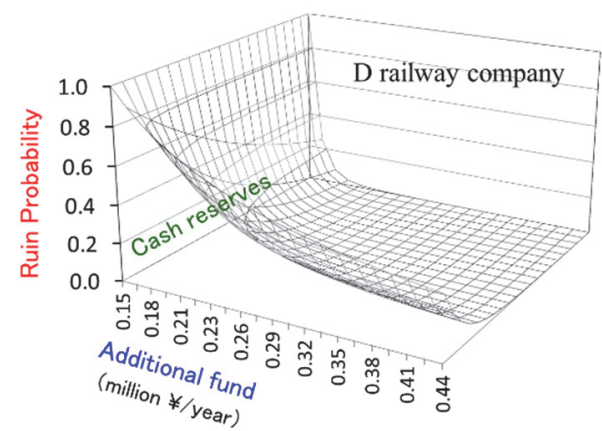

Fig.7 Ruin probability of RF for D railway company (FY2013).

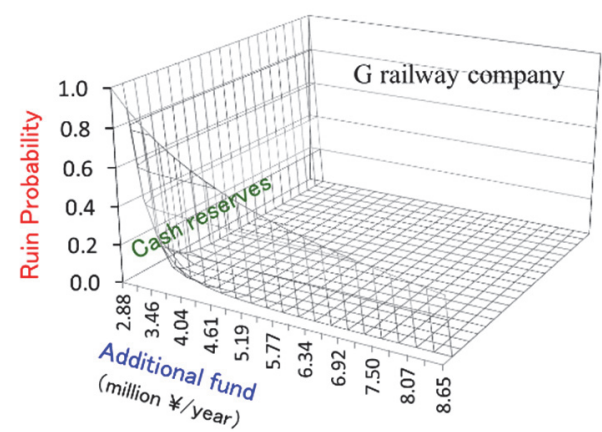

Fig.8 Ruin probability of RF for G railway company (FY2013). 
are discussed in the succeeding paragraphs.

Taking railway companies B, H, and J in Fig. 6 as examples, their total lengths of railway lines in use are about equal. However, we can see large differences in disaster characteristics and RF conditions as shown in Fig. 9. The RF of $\mathrm{H}$ railway company is smallest in spite of suffering from the largest impact of storm and flood disasters. In contrast, the RF of B railway company is largest, even though it suffers from the smallest impact of storm and flood disasters. Accordingly, the RF policies of these companies can be evaluated as unreasonable.

Figure 10 illustrates the ruin probabilities of RF for railway companies $\mathrm{B}, \mathrm{H}$, and $\mathrm{J}$ at the end of FY2013 with assuming the fund balance at the beginning of the same year as initial reserves. Here, the respective companies spend disaster restoration cost $E(S)$ on average per year, and the relative comparison can be achieved by using the safety loading factor $\theta$ which expresses the actual change rate of additional procurable funds. Figures 9 and $\mathbf{1 0}$ indicate the following two points:

1) For a given safety loading factor $\theta$, the greater the risk of storm and flood damage, the greater the ruin probability becomes.

2) For a given ruin probability, the greater the risk of storm and flood damage and the smaller the initial reserves, the greater the safety loading factor $\theta$ becomes.

As a result, the ruin probabilities calculated in this work reflect disaster characteristics and RF situations. Using these attributes of ruin probability enables the objective, scientific, and quantitative determination of the stability of risk management against storm and flood disasters.

\section{(3) Case studies on ruin probability in multiple railway businesses}

Let us consider a case wherein the eleven railway companies in Fig. 6 jointly manage and use their initial reserves and additional procurable funds for storm and flood disaster RF. If these companies have the same safety loading factor, the ruin probability of RF can be calculated using formula (64). As an example, the ruin probability in FY2013 as determined using actual FY1991-2012 data is shown in Fig. 11. If the fund balance (actual amount) is set as initial reserves at the beginning of FY2013, the ruin probability is a weighted average value of the risk of storm and flood disaster of the eleven railway companies as described in Section 4.(4). The ruin probability of each company is shown in Fig. 12. Consequently, the following points are understood concerning measures for improving RF in multiple railway businesses:

1) As displayed in Fig. 12, the ruin probability of a jointly managed business is considerably lower

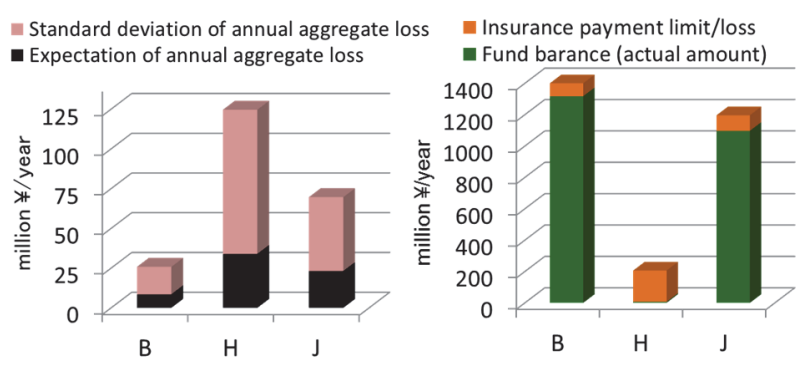

Fig.9 Storm and flood properties (left side), and risk-related financial conditions of $\mathrm{B}, \mathrm{H}, \mathrm{J}$ railway companies (right side, FY2013) (The working kilometer of the three companies is about equal.).

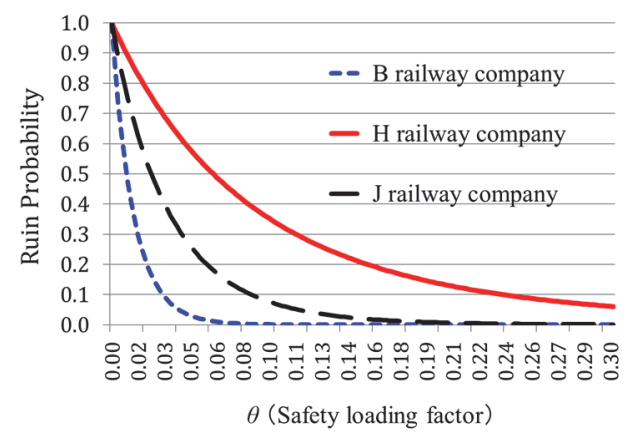

Fig.10 Ruin probability of RF for railway companies B, H, J (FY2013).

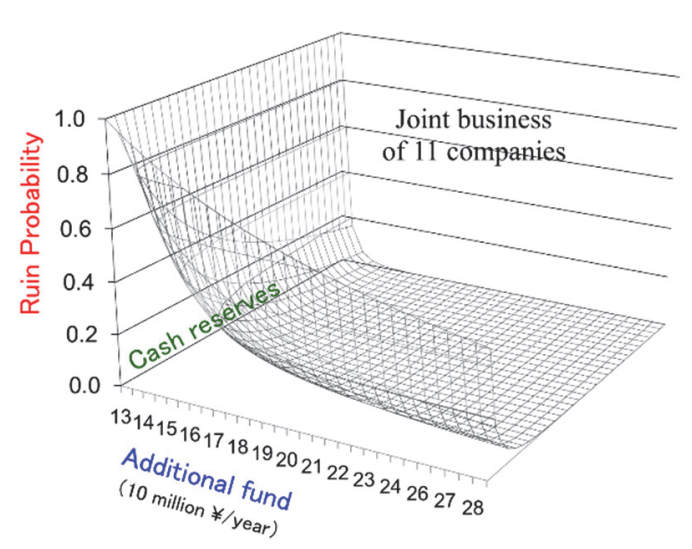

Fig.11 Ruin probability of RF for joint businesses among 11 companies (FY2013).

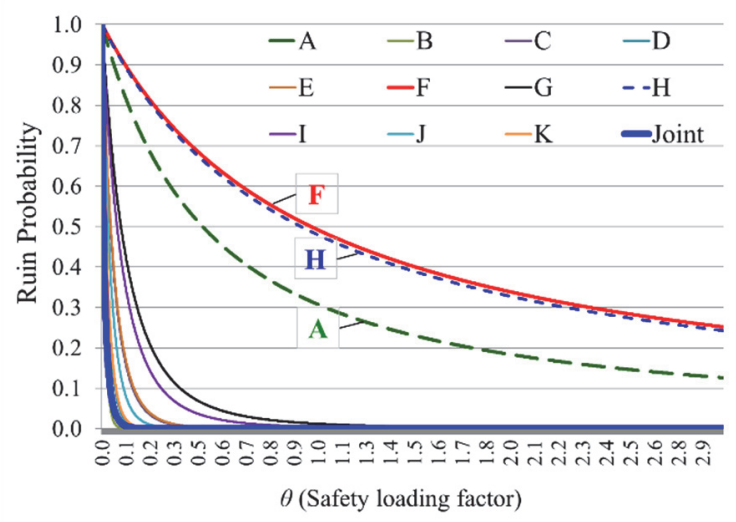

Fig.12 Ruin probability of each company and joint businesses based on initial reserves at the beginning of FY2013. 
than those of the examined companies. This result is attributed mainly to the scale merit of RF.

2) The ruin probabilities of railway companies $A, F$, and $\mathrm{H}$ are much higher than those of the other railway companies under the consideration of a safety loading factor $\theta$. The main reason is that the three companies have large storm and flood disaster risks or have almost no initial reserves.

3) The eight railway companies other than the abovementioned three railway companies have appreciably smaller ruin probabilities than those of the entire eleven railway companies in consideration of any safety loading factor $\theta$. This finding is ascribed principally to the differences in initial reserves among the companies (Fig. 13). That is, the initial reserves of the eight firms are more than 10 times larger than those of companies $\mathrm{A}, \mathrm{F}$, and $\mathrm{H}$.

4) As mentioned in items 2) and 3) above, to reduce the collective ruin probability of the entire eleven railway enterprises, a desirable strategy from the standpoint of fairness is to implement urgent RF measures for railway companies $\mathrm{A}, \mathrm{F}$, and $\mathrm{H}$. The prospective measures that the three companies can apply include substantially raising the insurance coverage limit in the short term and increasing initial reserves in the medium and long terms.

5) An example of a short-term measure is for companies $\mathrm{A}, \mathrm{F}$, and $\mathrm{H}$ to adopt a safety loading factor $\theta$ that is four times that applied by the other eight enterprises. In this situation, the ruin probability can be calculated using Theorem 2, as presented in Fig. 14. Based on such an estimation to plan the adjustment with the other eight companies, we can examine the favorable insurance coverage limit for $\mathrm{A}, \mathrm{F}$, and $\mathrm{H}$.

6) As an example of measure in medium-and longterm, the initial reserves of $\mathrm{A}, \mathrm{F}$, and $\mathrm{H}$ would be doubled the mean of all (eleven) railway companies. In this case, the ruin probability can be calculated using Theorem 2, as demonstrated in Fig. 15. Employing this estimation as basis in planning the adjustment with the other eight companies, the favorable initial reserves for $\mathrm{A}, \mathrm{F}$, and $\mathrm{H}$ can be examinated.

\section{CONCLUDING REMARKS}

\section{(1) Main results}

This study presents the ruin probability which serves as a mathematical foundation for making a management judgment every year on storm and flood disaster RF including initial reserves and insurance contracts with taking account of disaster characteristics and financial conditions of the respective railway companies. By using the proposed ruin probability
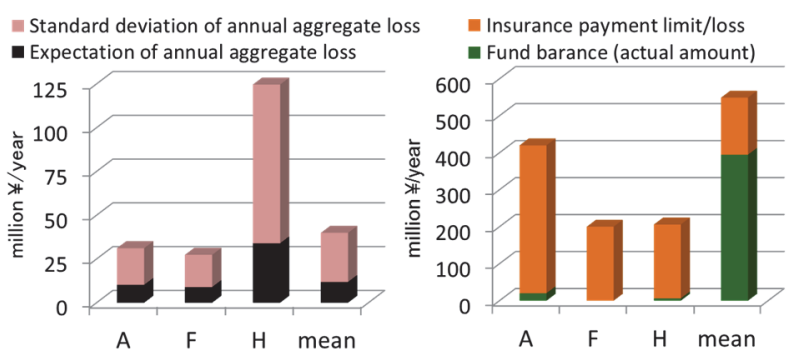

Fig.13 Storm and flood properties (left side), and risk-related financial conditions of railway companies A, F, H (right side, FY2013).

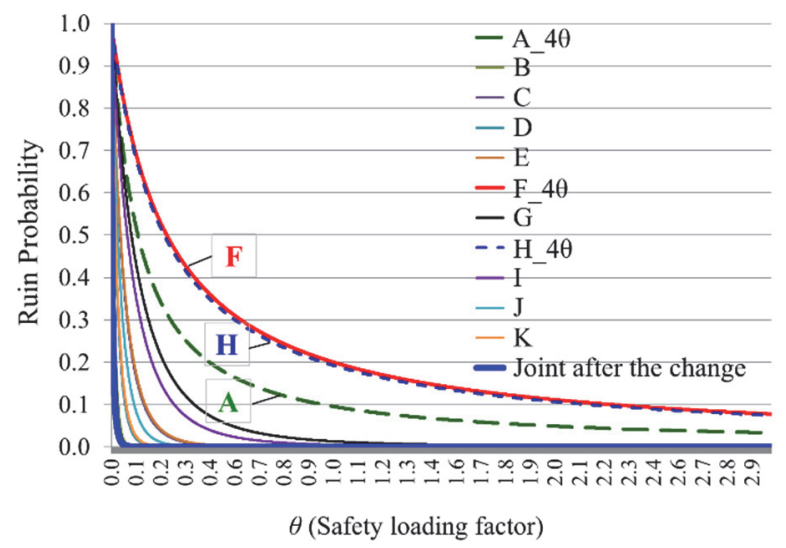

Fig.14 Ruin probability of each company and joint businesses based on initial reserves at the beginning of FY2013, with consideration for changes in the safety loading factors of $\mathrm{A}, \mathrm{F}$, and $\mathrm{H}$.

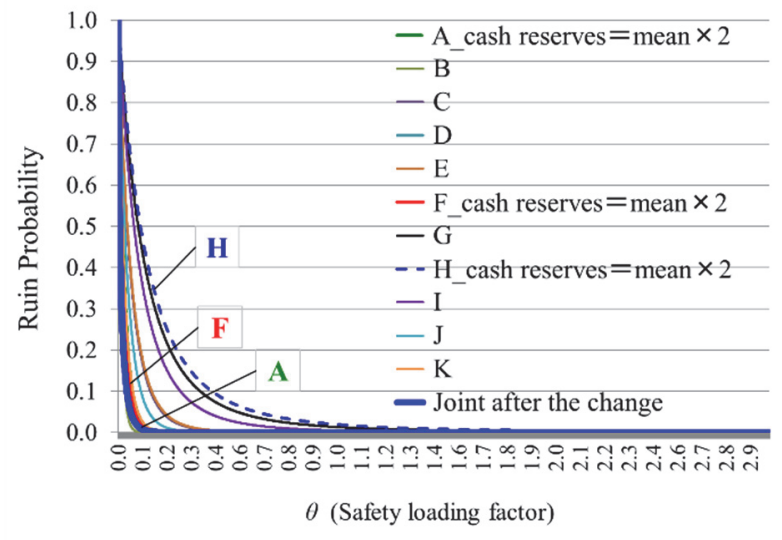

Fig.15 Ruin probability of each company and joint businesses based on initial reserves at the beginning of FY2013, with consideration for changes in the safety loading factors of $\mathrm{A}, \mathrm{F}$, and $\mathrm{H}$.

formulas such as Theorem 1 and Theorem 2, we can calculate scientifically the advantageous RF with considering disaster characteristics and financial condition of multiple railway businesses, in order to satisfy the actual needs of many railway companies as noted in Section 2.(3).

The specific outcomes of this study are classified 
into academic contributions and practical contributions.

\section{a) Academic contributions}

1) In Section 3.(3), the calculation model for the aggregate loss caused by storm and flood disasters has made possible to stochastically formulate and calculate aggregate loss of multiple railway businesses.

2) In Section 4, calculation formulas (64) and (72) are derived mathematically on ruin probability of RF against storm and flood disasters in cases wherein the disaster restoration costs are jointly managed by multiple railway businesses.

3) By means of Theorem 1 and Theorem 2, it is possible to analyze mathematically the ruin probability of the joint business by using varied parameters of each railway business. These theorems function as general calculation formulas that are composed of the parameters that underlie the disaster characteristics and financial conditions of each railway company.

4) In Section 5, an effective analysis method is specifically presented for RF against storm and flood disaster.

\section{b) Practical contributions}

In a practical meaning, the proposed ruin probability is a risk measure on whether the disaster restoration cost incurred in a fiscal year can be paid at the end of the fiscal year (accounting date). In other words, it means the stability of corporate management against storm and flood disasters.

As discussed in Section 5.(3), the major practical contributions of this study are as follows.

1) The solvency of jointly operated business with considering the differences in disaster characteristics and financial conditions of each railway business can be objectively and quantitatively analyzed.

2) Comparing the ruin probability of each railway business with that of a jointly operated business enables the numerical measurement of differences in the stability of corporate management against storm and flood disasters. Using this approach also facilitates the identification of critical problems associated with disaster characteristics and financial conditions (initial reserves and additional procurable funds) in cases wherein the ruin probability of RF is high.

3) In cases wherein gaps in the ruin probabilities of railway businesses are significant, it is very useful to consider the solution by meand of formula (72), focusing on the varied parameters of initial reserves, additional procurable funds, and disaster characteristics of each railway business.

\section{(2) Further development}

This research has reviewed RM for natural disasters in railway business and has concentrated on RF in preparation for storm and flood disasters, because of the large variances in probabilistic characteristics of storm and flood disasters, earthquakes, and tsunamis. As a result, it has becomed feasible to calculate the ruin probability of RF against storm and flood disasters in railway businesses.

For further development, RF designed to deal with natural disasters can be expanded by integrating losses caused by earthquakes and tsunamis into ruin probability calculations. Although techniques for estimating the damage that earthquakes and tsunamis cause to railway structures have gradually improved from the standpoint of engineering, ruin probability that reflects earthquake and tsunami induced damage remains one of the challenges for future study.

In addition, condition setting and analysis methods should be improved with due consideration of practical requirements.

ACKNOWLEDGMENT: I am thankful for the support extended by the Japan Transport and Tourism Research Institute. I would also like to express my sincere gratitude to all individuals who offered assistance in the completion of this study, particularly the railway officials who cooperated in the interview investigation and data collection. Finally, I am profoundly grateful to Dr. Shigeru Morichi, Dr. Toshinori Nemoto, and Dr. Takashi Yanagawa for the helpful advice and encouragement that they have given me.

Note (1) The author conducted 24 interviews with small and medium-sized railway companies, third-sector railway companies, the Thirdsector Rrailway Companies Association, Railway Bureau, and non-life insurance companies, as well as with risk engineering experts in 2014 to 2016 .

\section{REFERENCES}

1) Ohori, K. : A study on natural disaster risk finance in the railway business: Ruin probability and application, Transport Policy Studies' Review, Vol. 18, No. 2, pp. 69-73, 2015. (in Japanese)

2) Ohori, K. and Morichi, S. : Ruin probability on natural disaster risk finance in the railway business, Journal of Japan Society of Civil Engineers. F4, Vol. 72, No. 2, pp. 63-72, 2016. (in Japanese)

3) Ohori, K. : A study on natural disaster risk finance in the railway business: Historical review and fundamental analysis, Transport Policy Studies' Review, Vol. 19, No. 2, pp. 33-37, 2016. (in Japanese)

4) Uchida, S., Hirata, T., Matsuno, Y., Yoon, J. and Morichi, S. : Current status and issues of risk financing and role of public sector for post-disaster restoration of transportation facilities, Transport Policy Studies' Review, Vol. 12, No. 2, 
pp. 66-72, 2009. (in Japanese)

5) Morichi, S. : Institutional issues of infrastructure for risk, JSCE Magazine, Vol. 94, No. 8, p. 38, 2009. (in Japanese)

6) Nozawa, K., Hirata, T., Sueyoshi, T. and Sasaki, S. : Risk management and role of public sector for post-disaster restoration of transportation facilities, Transport Policy Studies' Review, Vol. 13, No. 3, pp. 85-92, 2010. (in Japanese)

7) Asian Development Bank : Operation for integrated disaster risk management 2014-2020, 2014.

8) Organization for Economic Co-operation and Development : Financial Management of Flood Risk, OECD publishing, 2016.

9) Railway Technical Research Institute : Railways and Natural Disasters, Nikkan Kogyo Shinbun, 2015. (in Japanese)

10) Ohta, N. and Sugiyama, T. : Change of natural disasters and future disaster management in railways, The Journal of Japan Railway Civil Engineering Association, June 2009. (in Japanese)

11) The International Organization for Standardization : ISO31000-Risk management; A practical guide for SMEs, ISO Copyright Office, 2015. (Retrieved March 7, 2017 from https://www.iso.org/files/live/sites/isoorg/files/archive/pdf/en/iso_31000_for_smes.pdf).

12) Japanese Standards Association : Summary of ISO 31000, 2017. (Retrieved March 1, 2017 from http://www.jsa.or.jp/ stdz/iso/mngment/risk03.html) (in Japanese).

13) Nakamura, T. and Ugata, T. : Seismic Risk Management, Gihodo Shuppan, 2009. (in Japanese)

14) Cabinet Office, Government of Japan : Disaster Management in Japan, 2015.

15) Ministry of Land, Infrastructure, Transport and Tourism : Cost-benefit analysis of flood control manual (draft), 2005. (in Japanese)

16) Kobayashi, K. and Yokomatsu, M. : Disaster risk management and economic evaluation, Infrastructure Planning Review, Vol. 19-1, pp. 1-12, 2002. (in Japanese)

17) Tatano, H. and Takagi, A. (eds.): Economic Analysis of Disaster Management, Keiso Shobo, 2005. (in Japanese)

18) Picard, P. : Natural disaster insurance and the equity-efficiency trade-off, The Journal of Risk and Insurance, Vol. 75, No. 1, pp. 17-38, 2008.

19) Foot, K. A. (ed.): The Financing of Catastrophe Risk, The University of Chicago Press, 1999.

20) McNeil, A. J., Frey, R. and Embrechts, P. : Quantitative Risk
Management: Concepts, Techniques, and Tools, Princeton University Press, 2005.

21) Stuart, A. K., Harry, H, P. and Gordon, E. W. : Loss Models from Data to Decisions, 3rd edition, Wiley, 2008.

22) Soren, A. and Hansjorg, A. : Ruin Probabilities, 2nd edition, World Scientific, 2010.

23) Ermoliev, Y., Ermolieva, T., MacDonald, G., Norkin, V. and Amendola, A. : A system approach to management of catastrophic risks, European Journal of Operational Research, Vol. 122, Issue 2, pp. 452-460, 2000.

24) Ermolieva, T., Ermoliev, Y. and Fischer, G. : The role of financial instruments in integrated catastrophic flood management, Multinational Finance Journal, Vol. 7, No. 3/4, pp. 207-230, 2003.

25) Amendola, A., Ermolieva, T., Linnerooth-Bayer, J. and Mechler, R. (ed) : Integrated Catastrophe Risk Modeling : Supporting Policy Processes (Advances in Natural and Technological Hazards Research), Springer, 2013.

26) Ermolieva, T., Filatova, T., Ermoliev, Y., Obersteiner, M., de Bruijn, K. M. and Jeuken, A. : Flood catastrophe model for designing optimal flood insurance program: Estimating location - specific premiums in the Netherlands, Risk Analysis, Vol. 37, Issue 1, pp. 82-98, 2017.

27) Nunokawa, O., Sugiyama, T., Mori, T. and Hata, A. : A method to determine the probability of investment in disaster prevention for rainfall-induced slope failure, Journal of Japan Society of Civil Engineers. C, Vol. 67, pp. 160-173, 2011. (in Japanese)

28) Omine, H., Yoshikawa, H., Yashiro, H. and Ohtaki, T. : Seismic risk evaluation of linear facility for risk finance, Journal of Japan Society of Civil Engineers. F6, Vol. 67, No. 1, pp. 14-26, 2011. (in Japanese)

29) Motoyama, H., Sakai, K., Izawa, J. and Murono, Y. : Development of earthquake disaster simulator for railways, RTRI REPORT, Vol. 30, No. 5, 2016. (in Japanese)

30) East Japan Railway Company : Financial report for investors, March 2011. (Retrieved March 7, 2017 from https://www.jreast.co.jp/investor/guide/pdf/201103guide1.pdf). (in Japanese)

31) The Third-Sector Railway Companies Association : History of 30 years, 2015. (in Japanese)

(Received April 17, 2017) 